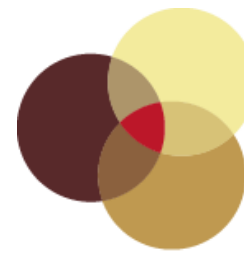

contennporaneity

Vol 7, No 1 (2018) ｜ＩSSN 2153-5914 (online) | DOI 10.5195/contemp/2018.238

http://contemporaneity.pitt.edu

\title{
Coming to Confidence
}

\author{
Cecelia Ivy Price
}

\begin{abstract}
About the Artist
Cecelia Ivy Price is a Cleveland, $\mathrm{OH}$-based artist. Price is the recipient of multiple scholarships, including two that enabled her travel to Italy for art history programs based in Florence and Rome and one for her work titled "Halfrican, "relating to multicultural self-expression. Her work explores the power of skeletons and vanitas ("vanity"), which demonstrate life's impermanence, the plausible insignificance of earthly life, and the transient nature of all earthly goods and pursuits. Price channels the certainty of death and the imperative of not letting life pass one by. These ruminations grew deeper after the passing of the artist's mother in 2012. She spoke at the Skeletons, Stories, and Social Bodies Conference at the University of Southampton in 2018 on her works surrounding her mother's death in "Pins and Needles," which was featured in the series "Grave Expressions." As part of the Artist in Residence Program, she is creating works of art from reference photos she took while abroad. Interested parties can find Cecelia's creation of one these works, based on a Roman Cello Player, on her nascent YouTube channel, IvyArtisticChaos.
\end{abstract}




\section{Coming to Confidence}

\author{
Cecelia Ivy Price
}

I am baffled by Americans' inability to see the nude form for what it is: raw, pure, natural; simply beautiful. My work addresses subjects such as body shaming and self-confidence issues. I see the nude form as perfection, even with all of its natural, individual flaws. I paint sensuous, undulating lines of fleshy human forms, often with faces cut off or nondescript. We should not be living in a society that forces an art teacher to glue pages of art history books together so the students do not see the same naked figures they should have learned about in biology class. I think the nudity and skulls in my work are reminders that we are all different and all the same, at once. We are all skeletons underneath, and we are all naked under our clothes; what is different is our personalities. This body of work also touches on sexual abuse, a nuance some viewers have not recognized.

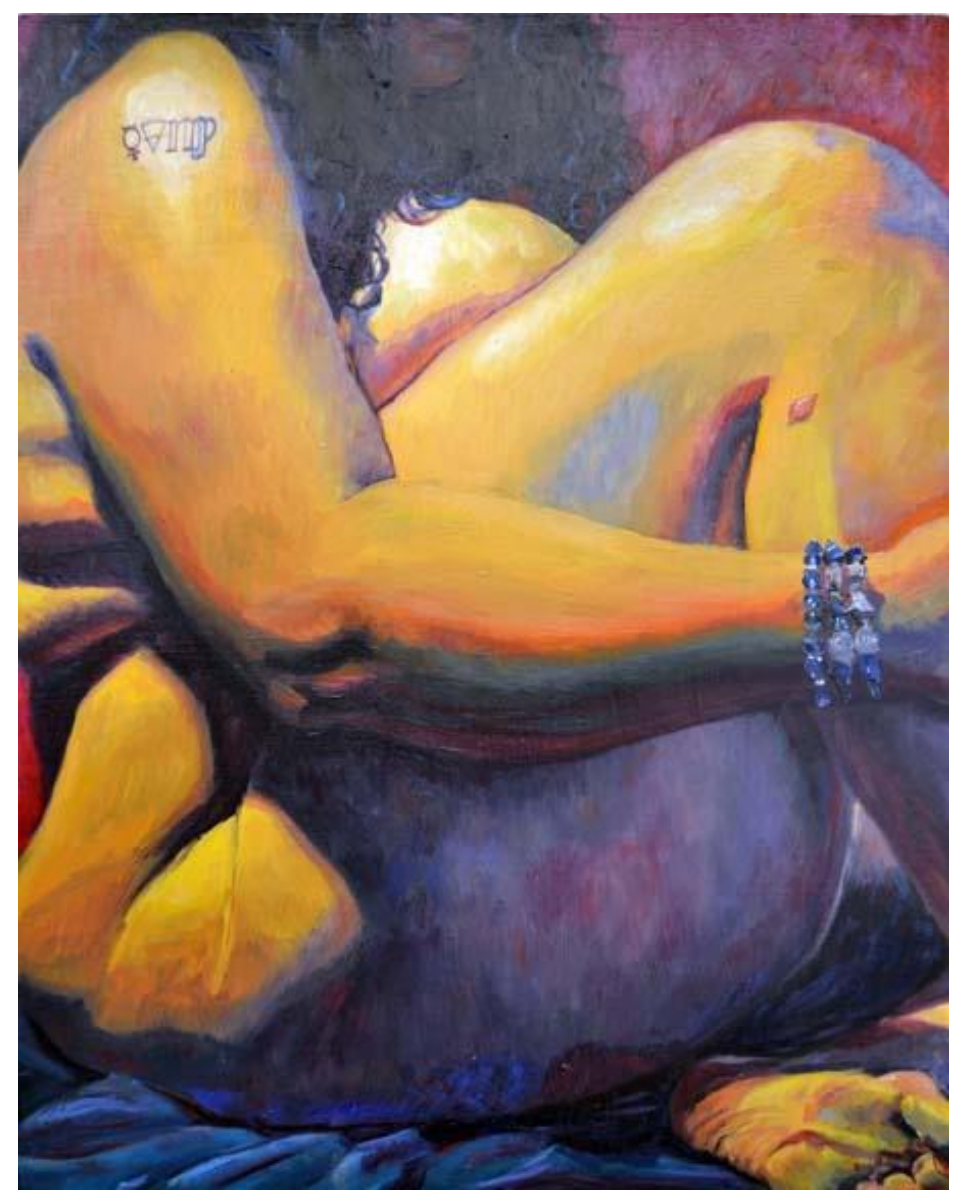

Figure 1

Cecelia Ivy Price, Coming to Confidence I, 2014, Oil on Canvas. 


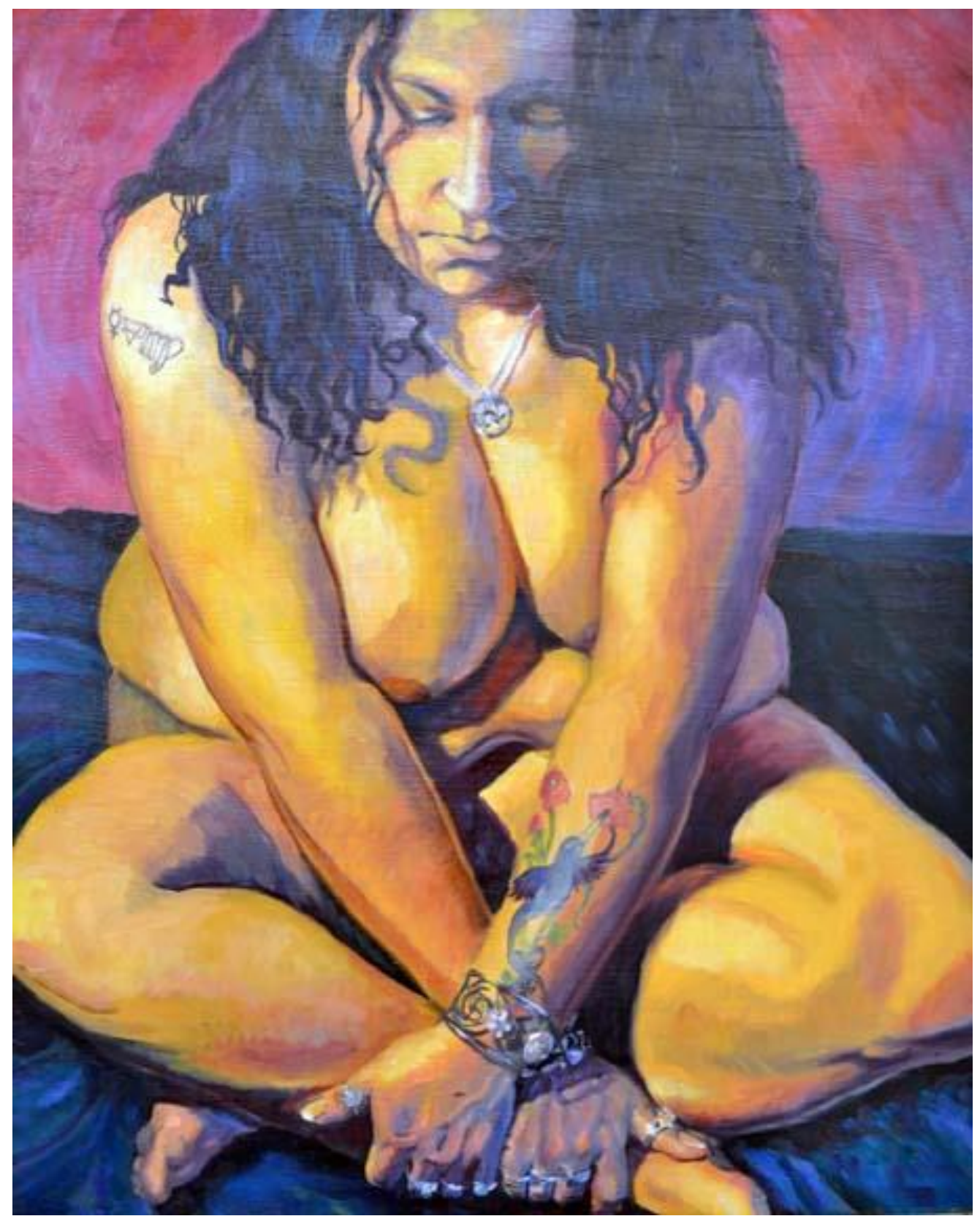

Figure 2

Cecelia Ivy Price, Coming to Confidence II, 2014, Oil on Canvas. 


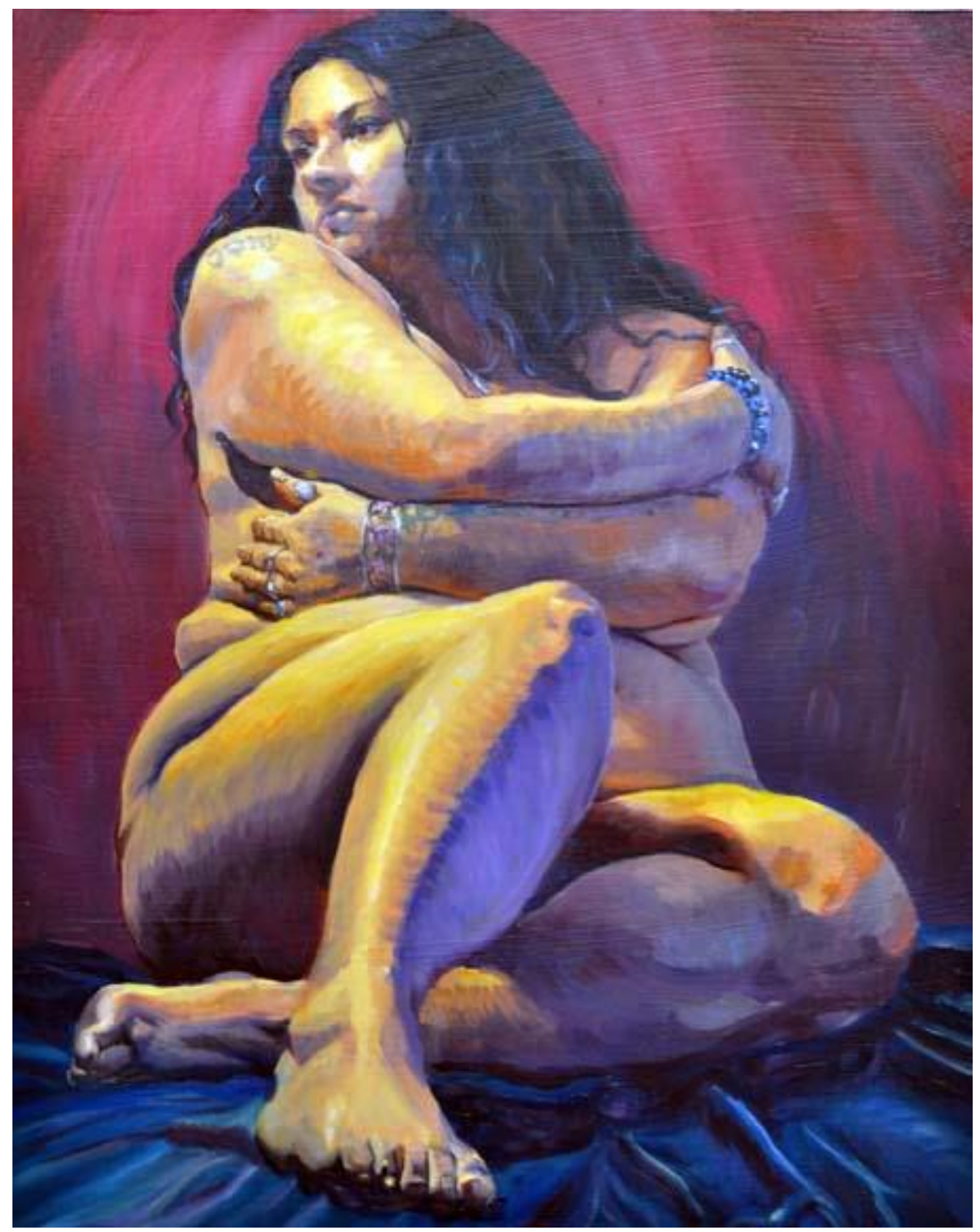

Figure 3

Cecelia Ivy Price, Coming to Confidence III, 2014, Oil on Canvas. 


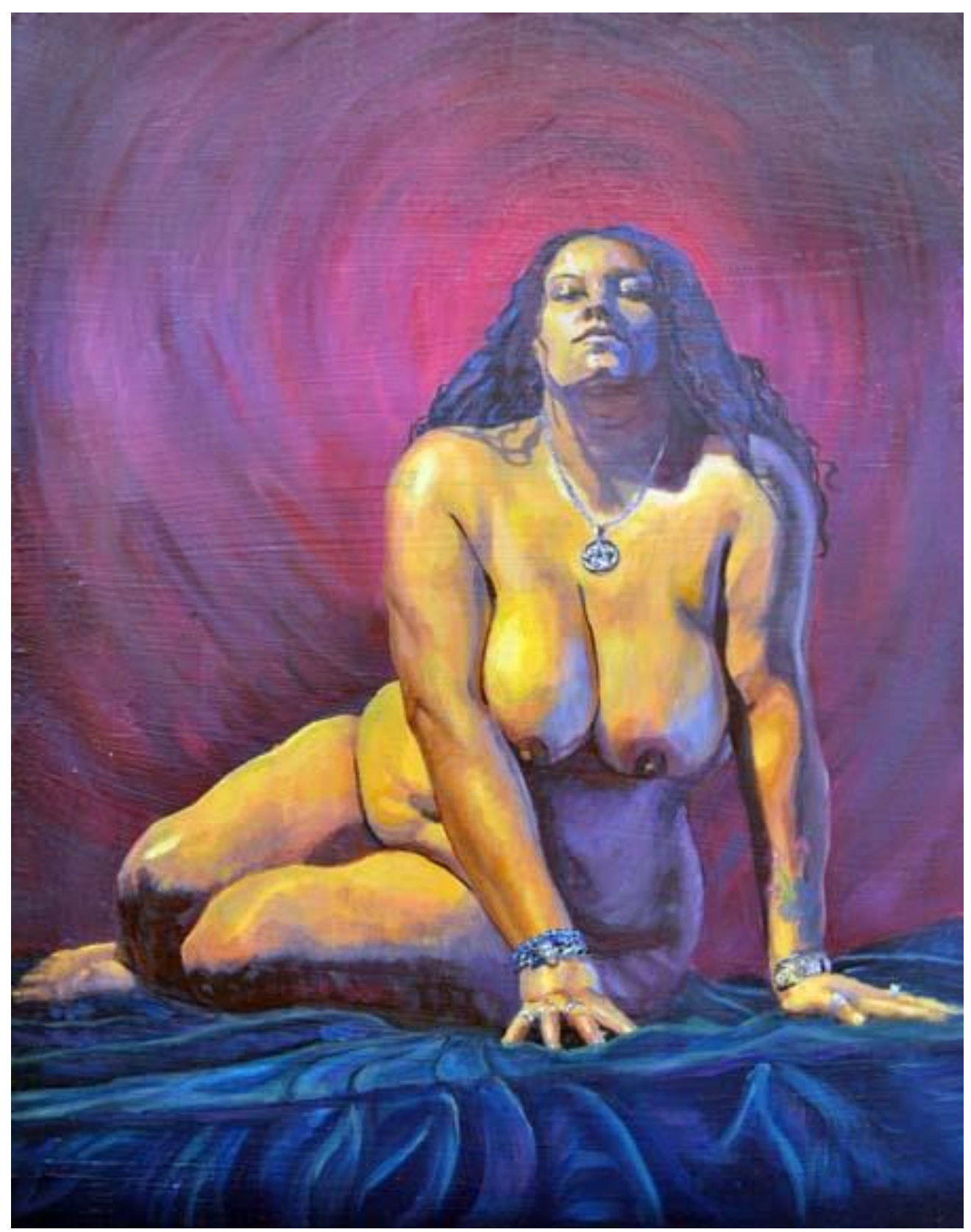

Figure 4

Cecelia Ivy Price, Coming to Confidence IV, 2014, Oil on Canvas.

(cc) EY

New articles in this journal are licensed under a Creative Commons Attribution 4.0 United States License.

\section{UILIS D-Surk}

This journal is operated by the University Library System of the University of Pittsburgh as part of its D-Scribe Digital Publishing Program, and is co-sponsored by the University of Pittsburgh Press. 